\title{
THE ROLE OF APOPTOSIS PROTEINS AND COMPLEMENT COMPONENTS INTHE ETIOPATHOGENESIS OF SYSTEMIC LUPUS ERYTHEMATOSUS
}

\author{
Bernadete L. Liphaus, Maria Helena Bittencourt Kiss
}

doi: 10.1590/S1807-59322010000300014

Liphaus BL, Kiss MHB. The role of apoptosis proteins and complement components in the etiopathogenesis of systemic lupus erythematosus. Clinics. 2010;65(3):327-33.

\begin{abstract}
Systemic lupus erythematosus is a prototypical autoimmune disease characterized by the deregulation of $\mathrm{T}$ and $\mathrm{B}$ cells, tissue infiltration by mononuclear cells, tissue damage and the production of autoantibodies. There is a consensus that accelerated apoptosis of circulating lymphocytes and/or impaired clearance of apoptotic bodies may increase the amount of nuclear antigens presented to $\mathrm{T}$ lymphocytes. This process is accompanied by autoimmune responses that can lead to the development of lupus. The dysfunction of apoptosis may be a direct consequence of alterations in proteins/genes such as Fas, Bcl-2 and C1q. Increased expression of Fas antigen could intensify the exposure of hidden antigens. The overexpression of Bcl-2 protein might inhibit the removal of autoreactive cells, and the lack of C1q could impair the clearance of self-antigens. The complete knowledge of the role of apoptosis components in the etiopathogenesis of lupus could lead to the development of new therapies targeting the apoptotic threshold, which could result in a more specific and effective disease response compared to global immunosuppression. This review summarizes the role of each component of the apoptotic process in the pathogenesis of lupus.
\end{abstract}

KEYWORDS: Systemic Lupus Erythematosus; Apoptosis; Fas protein; Bcl-2 protein; C1q complement component.

\section{INTRODUCTION}

Systemic lupus erythematosus (SLE) is a prototypical autoimmune disease characterized by deregulations of $\mathrm{T}$ and B cells causing the production of autoantibodies, immunecomplex deposition, tissue infiltration by mononuclear cells such as macrophages, and tissue damage. ${ }^{1-3}$ These immunological deviations can lead to a high morbidity and mortality, especially in childhood. ${ }^{1-3}$ The etiopathogenesis of SLE is not yet fully understood, but abnormalities of the apoptotic process are considered be related to the development of the disease. ${ }^{1,2} \mathrm{~A}$ delayed clearance of apoptotic cells was demonstrated in lupus patients. ${ }^{1,2,45}$ The impaired clearance of apoptotic debris by phagocytes can occur due to a specific

Department of Pediatrics, Faculdade de Medicina da Universidade de São Paulo - São Paulo/SP, Brazil.

Email: bernadete.liphaus@icr.usp.br

Tel.: 55113069.8606

Received for publication on September 15, 2009

Accepted for publication December 01, 2009 abnormality in the receptors of these cells, ${ }^{6}$ the influence of a serum factor, ${ }^{7}$ reduced opsonization of apoptotic bodies ${ }^{6,7}$ or a decreased number of phagocytic cells. ${ }^{89}$ Moreover, accelerated apoptosis of circulating cells is observed in SLE patients, and during this process specific lupus autoantigens, such as dsDNA, are exposed on surface blebs..$^{1,3-5}$ The accelerated apoptosis may be a direct consequence of alterations in proteins/genes related to programmed cell death, such as Fas and Bcl-2. Increased expression of Fas antigen might intensify the exposure of hidden antigens, and the overexpression of Bcl-2 protein could inhibit the removal of auto-reactive cells ${ }^{1,2}$. These protein alterations might generate a pro-inflammatory status that overrides the mechanisms of tolerance, thus leading to lupus. ${ }^{1,2,10}$ This review summarizes the role of each component of the apoptotic process in the pathogenesis of lupus.

\section{Apoptotic process}

Apoptosis or programmed cell death is a genetically 
conserved pathway and a regular feature in normal tissue homeostasis. ${ }^{5,11}$ Blood, epithelial and endothelial cells have especially high rates of turnover and must be promptly recognized for disposal. ${ }^{11}$ The main characteristics of the apoptotic phenomenon are membrane blebbing, the cleavage of DNA and the degradation of cellular components. ${ }^{5}$ During apoptosis, intracytoplasmatic proteins are cleaved, and some of them are phosphorylated while others are redistributed. ${ }^{5}$ It has also been described that during apoptosis an increased amount of DNA shows abnormal methylation and GC content. ${ }^{12}$ The abnormal methylation of DNA can enhance its potential to activate murine and human B lymphocytes. ${ }^{12}$ It is believed that apoptotic cells are efficiently removed by reticuloendothelial cell system recognition of surface receptors such as scavenger receptor $\mathrm{A}$ (CD36) and the phosphatidilserine receptor (CD68). ${ }^{5,11}$ Some of these receptors also exert an influence on the cytokines generated by phagocytes. ${ }^{11}$ In addition to surface receptor recognition, a number of proteins, e.g., components of the complement system, could act as opsonins for phagocytes. ${ }^{13}$ Apoptosis is also essential for the establishment of tolerance, as demonstrated by Ferguson's ${ }^{10}$ studies on the eye, the prototypical immune-privileged organ. Programmed cell death might happen without being noticed by the immune system and consequently without inflammation. ${ }^{10}$ Nevertheless, inefficient disposal of dying cells or release of pro-inflammatory cytokines by lymphocytes during the engulfment of apoptotic bodies could lead to the activation of T cells. ${ }^{10}$ Therefore, self proteins or self-modified proteins could be presented to or could activate $\mathrm{T}$ cells, thus leading to autoimmunity. ${ }^{1,5}$ However, peripheral tolerance mechanisms, such as regulatory $\mathrm{T}$ cells (Tregs), would restrain the autoimmune process. In addition, the apoptosis of lymphocytes during thymic selection would limit the presence of auto-reactive $\mathrm{T}$ lymphocytes in the periphery. ${ }^{4,5,10,14,15}$ It is now believed that dendritic cells, which are well-equipped to present self and non-self antigens to $T$ cells via human leukocyte antigen (HLA) classes I and II, are also fundamental for establishing tolerance. ${ }^{1,5}$ The major histocompatibility complex (MHC) genotype determines which $\mathrm{MHC}$ molecules are available to the antigens and thus how well the antigens can be recognized by $\mathrm{T}$ cells. Particular MHC genes have been associated with an increased risk of an immune response to self-antigens and hence an increased risk of disease development, such as that observed in SLE patients. . $^{3,16,17}$

There is now enough evidence to consider genetic or immune disturbance of the apoptotic process as the main factor in the development of lupus. ${ }^{1,14}$ From this perspective, accelerated apoptosis of circulating lymphocytes and/or impaired clearance of apoptotic cells in patients with lupus might lead to an increased amount of intact nuclear antigens or modified proteins in the extra-cellular tissue. These selfantigens could be presented by dendritic cells to peripheral auto-reactive $\mathrm{T}$ lymphocytes, thus driving an autoimmune response. ${ }^{10}$ Additionally, B cells producing autoantibodies could avoid apoptosis, thereby maintaining their activated state. $^{1,4}$

It has been observed that lupus-specific autoantigens, including dsDNA, are exposed on the surface of apoptotic cells. ${ }^{1,5}$ Casciola-Rosen et al. ${ }^{18}$ demonstrated that UVBirradiated keratinocytes undergo apoptosis and that lupus autoantigens such as 60-Kd Ro and La are strikingly redistributed, becoming concentrated on surface blebs. Additionally, Emlen et al. ${ }^{19}$ and Courtney et al. ${ }^{20}$ observed increased numbers of circulating apoptotic leukocytes and lymphocytes in SLE patients. Another study showed that lymphocytes from lupus patients undergo apoptosis at a significantly greater rate than lymphocytes from healthy controls. ${ }^{21}$ Moreover, adult patients with lupus present accelerated apoptosis of monocytes and consequently a decreased survival of these cells. ${ }^{89}$ Kaplan et al. ${ }^{9}$ showed that the autologous monocyte death is mediated by apoptotic ligands, i.e., TRAIL, TWEAK and FasL. These observations suggest that both an increase of circulating apoptotic bodies and a decreased clearance of apoptotic debris by phagocytic cells might occur in SLE pathogenesis.

The decreased function of phagocytic cells can also occur as a consequence of specific abnormalities in membrane receptors. ${ }^{11}$ Mice deficient in factors such as DNaseI, SAP, C1q, IgM and Mer, all of which are required for proper binding and clearance of apoptotic cells, spontaneously develop anti-nucleosome antibodies and glomerulonephritis. ${ }^{22}$ However, the former hypothesis was not supported by Bijl et al., ${ }^{6}$ who observed similar expression of CD14, CD18, CD36 or CD51/61 on monocytes from lupus patients and from healthy subjects. These authors concluded that the reduced uptake of apoptotic cells by monocyte-derived macrophages from patients with SLE was not an intrinsic defect, but was serumdependent and associated with decreased levels of C1q, C4 and $\mathrm{C} 3{ }^{6}$

From this point of view, the delayed clearance of apoptotic cells may provide self-antigens with access to antigen-presenting cells from which they were normally excluded. Most importantly, impaired clearance of apoptotic lymphocytes by macrophages has been demonstrated in both lupus-prone mice and patients. ${ }^{23,24}$ In addition, accumulation of apoptotic debris in lymph node germinal centers and an increased proportion of apoptotic Fas-expressing cells among bone marrow CD34+ hematopoietic progenitor cells were observed in SLE patients. ${ }^{25,26}$ The presence of uncleared 
apoptotic material at sites of B-cell and T-cell selection may explain the loss of tolerance observed in these patients. Although apoptosis is a well-accepted factor for lupus development, it is not well established how the observed abnormalities trigger autoimmunity.

\section{Fas and Bcl-2 proteins}

Apoptosis is induced by a range of stimuli that activate two major cell death signaling pathways: the intrinsic pathway controlled by Bcl-2 family members and the extrinsic cell death pathway controlled by death receptors of the tumor necrosis factor receptor super-family. ${ }^{5}$

Apoptosis depends both on coordinated action between proteins inducing and inhibiting the process and on the activation of caspases that cleave the DNA. ${ }^{2,4,5}$ Furthermore, the relationship between the inducers and inhibitors of apoptosis may differ according to cell type. Disturbance of the expression of Fas, FasL, Bcl-2, Bim, Bcl-X, Mcl-1 and TACI could lead to the accumulation of apoptotic bodies. ${ }^{2,5,10}$ Fas receptor and $\mathrm{Bcl}-2$ protein have significant roles in lymphocyte selection, proliferation, survival and death., ${ }^{4,5}$

It is well-known that Fas-FasL interactions play an essential role in maintaining the homeostasis of the immune system. ${ }^{5}$ Fas (APO1/CD95) is an apoptosis-promoting cell surface receptor. ${ }^{5}$ It was first described in MRL/Ipr mice with a Fas gene mutation that prevented cell death. These mice developed a lymphoproliferative syndrome with features resembling human SLE. ${ }^{27}$ In addition, Suda et al. ${ }^{28}$ showed that the murine lupus model MRL/gld presented a mutation at the FasL gene that prevented its expression.

Increased lymphocyte Fas expression has been reported in patients with lupus. ${ }^{20,29-31}$ These studies found an increased expression of Fas on $\mathrm{T}$ and B lymphocytes from SLE patients and demonstrated a positive correlation with disease activity. ${ }^{29,31}$ Amasaki et al. ${ }^{30}$ observed increased expression of Fas in both CD4+ and CD8+ T-cell subtypes from SLE patients when compared to healthy controls. Additionally, Suzuki et al. ${ }^{32}$ observed high expression of FasL on lymphocytes from lupus patients. Soluble Fas (sFas) is a variant of the Fas receptor lacking the transmembrane region. It has been detected in human sera and was found to inhibit apoptosis induced by Fas protein. ${ }^{5}$ This soluble form of Fas causes splenomegaly and lymphadenopathy when injected into normal mice. ${ }^{20,33}$ Patients with SLE show increased levels of sFas when compared to healthy controls, and a positive correlation was also shown between sFas, leucopenia and anti-dsDNA antibodies. ${ }^{19,33,34}$ Together, these data suggest that high expression of Fas antigen on lymphocytes might lead to rapid cell turnover and to increased exposure of the immune system to autoantigens, thus leading to autoimmune disease. ${ }^{1,4}$ Additionally, because sFas can suppress Fas-mediated apoptosis, it has been suggested that sFas can help autoreactive thymocytes to escape negative selection. ${ }^{34}$ However, the positive correlation between sFas level and dsDNA antibodies suggests a prorather than an anti-apoptotic activity of sFas. Telegina et al. ${ }^{34}$ described that the oligomeric form of sFas stimulates apoptotic cell death, and that its levels are increased in sera from lupus patients when compared to the monomeric form. The exact function of sFas in the pathogenesis of SLE remains to be established.

Although Fas-mediated lymphocyte apoptosis is a well-known source of autoantigens, gene abnormalities in other cell death pathways cannot be ruled out. Habib et al. ${ }^{35}$ showed that $\mathrm{T}$ lymphocytes from lupus patients presented enhanced apoptosis in the presence of TNF $\alpha$, independent of the Fas-FasL pathway. Pyrovolaki et al. ${ }^{26}$ demonstrated that the proportion of CD40-expressing CD34+ cells was significantly increased in SLE patients. These authors also observed a cooperative interaction of CD40 and Fas pathways in the promotion of apoptosis of CD34+ cells. ${ }^{26}$

The Bcl-2 protein inhibits multiple forms of apoptosis and plays a pivotal role in the regulation of apoptosis in several cell types, including human $\mathrm{B}$ and $\mathrm{T}$ cells. ${ }^{5} \mathrm{Bcl}-2$ expression is tightly regulated in $\mathrm{T}$ lymphocytes, monocytes and neutrophils, which suggests a critical role of this protein in cell death. ${ }^{5,36}$ Overexpression of Bcl-2 protein in transgenic mice protects B cells against cell death and promotes the development of a lupus-like autoimmune syndrome with nephritis and autoantibodies such as antidsDNA and anti-Sm. ${ }^{37}$

The expression of the apoptosis-inhibiting protein Bcl-2 in freshly isolated lymphocytes from lupus patients has been a controversial matter. Some investigations have shown increased Bcl-2 expression in T cells but not in B cells, while others demonstrated unaltered Bcl-2 quantities in unfractionated lymphocytes from adults with SLE. ${ }^{22,38,39}$ Miret et al. ${ }^{40}$ observed high levels of serum Bcl-2 in patients with active SLE when compared to patients with the inactive disease. Increased expression of Bcl-2 in lymphocytes might inhibit the removal of auto-reactive cells that could remain viable and thus be selected for further differentiation.

Studies involving juvenile-onset SLE patients are rare. Falcini et al. ${ }^{41}$ observed an increased expression of Bcl-2 protein in T lymphocytes. Additionally, Liphaus et al. showed an increased expression of Fas protein in CD3+, CD4+, CD8+ and CD19+ cells in juvenile-onset SLE patients when compared to healthy controls and to patients with juvenile rheumatoid arthritis or juvenile dermatomyositis. ${ }^{42} \mathrm{Bcl}-2$ expression was also higher in T lymphocytes from juvenileSLE patients, but not in B cells, when compared to healthy 
individuals. ${ }^{42}$ In addition, there was a positive correlation between Fas and Bcl-2 expression in B cells and disease activity; different profiles of these proteins were demonstrated in patients with active and inactive disease. ${ }^{43}$

The study of abnormalities in the expression of proteins related to apoptosis can be important not only for understanding the etiopathogenesis of lupus but also for contributing to its therapy. ${ }^{3,11,14}$ Seki et al. ${ }^{44}$ observed that SLE patients who are resistant to steroid therapy presented increased expression of Bcl-2 in CD8+ T cells. This study provided an important strategy for stratifying patients for therapeutic intervention.

At present, the role of apoptosis in the pathogenesis of SLE is thought to primarily consist of accelerated apoptosis and impaired clearance of apoptotic bodies, which lead to increased amounts of antigens that can be presented to immunocompetent cells. There is substantive evidence in the literature implicating apoptotic debris in disease development. Apoptosis is mediated by many proteins, although the role of each component and their interactions are not fully established. Increased expression of Fas antigen has been documented and explained, but the increased expression of $\mathrm{Bcl}-2$ protein still requires more interpretation. One possible reason for this could be that the elevation of Fas is quantitatively or qualitatively more important than that of Bcl-2, or that other factors could play a role in the activation of Fas or Bcl-2 proteins.

\section{C1q deficiency}

Although homozygous complement deficiencies are rare conditions, lupus develops in more than $90 \%$ of C1qdeficient individuals, and complement deficiencies are the strongest single genetic risk factor for the development of this disease. ${ }^{3,13,45-47} \mathrm{C} 1 \mathrm{q}$-deficient patients tend to present the disease at a young age, and there is no female predominance, which supports the notion that no other genetic factor is involved. ${ }^{46,47}$ This strong association invokes the role of complement in physiological waste disposal, particularly in the processing and clearance of dying cells and immune complexes. ${ }^{13,47-49}$ It has been demonstrated that $\mathrm{C} 1 \mathrm{q}$ binds to surface blebs of apoptotic human keratinocytes and that $\mathrm{C} 1 \mathrm{q}$ is essential for the proper clearance of apoptotic cells, which are considered as the primary source of self antigens that break tolerance during SLE development. ${ }^{6,45,46,48-50}$ Another hypothesis proposes that complement also plays a role in the activation of $\mathrm{B}$ and $\mathrm{T}$ lymphocytes, and that complement deficiency can cause autoantibody production by impairing the normal mechanisms of tolerance ${ }^{49,51-53}$ It was also shown that $\mathrm{Clq}$ is a potent modulator of dendritic cells, resulting in an impaired capacity for cytokine production, down-regulation of costimulatory molecules and a limited T-cell response. ${ }^{54} \mathrm{In}$ addition, the binding of $\mathrm{C} 1 \mathrm{q}$ results in complement activation, causing opsonization of apoptotic cells with $\mathrm{C} 4 \mathrm{~b}$ and $\mathrm{C} 3 \mathrm{~b}$. This opsonization will further accelerate their uptake by phagocytes and contribute to additional anti-inflammatory responses. ${ }^{49}$ The former observations can explain why other complement component deficiencies have also been associated with lupus. ${ }^{13}$ Botto et al.$^{55}$ demonstrated impaired clearance of apoptotic cells and development of severe glomerulonephritis and multiple autoantibodies in C1q-knockout mice. The important role of complement in apoptosis is further supported by data showing that the addition of complement components to an in vitro phagocytosis assay using human macrophages and apoptotic lymphocytes generated more than a threefold increase in the uptake of apoptotic cells. ${ }^{53}$ This finding is corroborated by the report of the reduced clearance of immune-complex in the spleen of a patient with $\mathrm{C} 2$ deficiency and lupus. The impaired uptake was restored by normalizing $\mathrm{C} 2$ levels with the use of fresh-frozen plasma. ${ }^{56}$ Another study demonstrated that IgM binds apoptotic cells and recruits $\mathrm{C} 1 \mathrm{q}$ and $\mathrm{C} 3 \mathrm{~b}$, contributing to their clearance. ${ }^{57}$ Although there is a strong link between C1q and SLE, most patients do not have a primary deficiency of complement. Low levels of $\mathrm{C} 1 \mathrm{q}$ are often due to the consumption of early complement components associated with the presence of antiC1q antibodies ${ }^{50,54,58}$ Bigler et al. ${ }^{59}$ demonstrated that anti-C1q antibodies from SLE patients specifically target C1q bound on early apoptotic cells, which might alter the clearance of these dead cells and enhance the proinflammatory immune response. The presence of anti-C1q antibodies has also been tightly linked to the occurrence of severe lupus nephritis, although there is still some controversy. ${ }^{50,58}$ Collectively, these data show that the early components of the classical complement pathway have a critical role in waste disposal of apoptotic cells and a crucial protective activity against lupus development.

The presence of anti-C1q antibodies may suggest the modification of $\mathrm{Clq}$, either genetically or by the apoptotic environment. The binding of $\mathrm{C} 1 \mathrm{q}$ to anti-C1q will result in complement activation and tissue damage. Given this rationale, $\mathrm{C} 1 \mathrm{q}$ deficiency should protect against lupus; nevertheless, in reality, C1q deficiency is strongly related to the development of the disease. Thus, C1q deficiency may be an important human model for better understanding of the impaired clearance of apoptotic bodies.

Autoantibodies are considered a hallmark in lupus patients. All of the mechanisms described above suggest the presence of hidden or modified antigens that could elicit autoantibodies. However, some questions still remain to be answered. For example, autoantibodies also occur in healthy people and in other autoimmune diseases, such as juvenile 
rheumatoid arthritis and dermatomyositis, where they are not considered pathogenic. Autoantibodies are also able to opsonize dead cells, facilitating their ingestion by professional phagocytes. Investigation into the above questions may clarify the role of autoantibodies in the pathogenesis of lupus and introduce a new branch of research.

\section{CONCLUSION}

Taken together, these findings suggest that deregulations of apoptotic phenomena and deficiencies of early components in the complement pathway have a critical role in the increased exposure of self-antigens. This is currently considered the main hypothesized mechanism for the development of lupus. The discovery of new factors involved in the apoptosis process and identification of potentially different roles for proteins already known to be related to SLE pathogenesis are challenges that still need to be addressed.

\section{REFERENCES}

1. Andrade F, Casciola-Rosen L, Rosen A. Apoptosis in Systemic Lupus Erythematosus. Clinical Implications. Rheum Dis Clin of North Am. 2000;26:215-27.

2. Munoz LE, van Bavel C, Franz S, Berden J, Herrmann M, van der Vlag $\mathrm{J}$. Apoptosis in the pathogenesis of systemic lupus erythematosus. Lupus. 2008; $17: 371-5$

3. Rahman A, Iseberg DA. Mechanisms of Disease. Systemic Lupus Erythematosus. N Engl J Med. 2008;358:929-39.

4. Kamradt T, Mitchinson NA. Advances in immunology: Tolerance and Autoimmunity. N Engl J Med. 2001;344:655-64.

5. Green DR. Overview: apoptotic signaling pathways in the immune system. Immunological Reviews. 2003;193:5-9.

6. Bij1 M, Reefman E, Horst G, Limburg PC, Kallenberg CGM. Reduced uptake of apoptotic cells by macrophages in systemic lupus erythematosus: correlates with decreased serum levels of complement. Ann Rheum Dis. 2006;65:57-63.

7. Ren Y, Tang J, Mok MY, Chan AWK, Wu A, Lau CS. Increased Apoptotic Neutriphils and Macrophages and Impaired Macrophage Phagocytic Clearance of Apoptotic Neutriphils in Systemic Lupus Erythematosus. Arthritis Rheum. 2003;48:2888-97.

8. Shoshan Y, Shapira I, Toubi E, Frolkis I, Yaron M, Mevorach D. Accelerated Fas-Mediated Apoptosis of Monocytes and Maturing Macrophages from Patients with Systemic Lupus Erythematosus: Relevance to In Vitro Impairment of Interaction with iC 3b-Opsonized Apoptotic Cells. J Immunol. 2001;167:5963-9.

9. Kaplan MJ, Lewis EE, Shelden EA, Somers E, Pavlic R, McCune WJ, et al. The Apoptotic Ligands TRAIL, TWEAK, and Fas ligand Mediate Monocyte Death Induced by Autologous Lupus T Cells. J Immunol. 2002;169:6020-9.

10. Ferguson TA, Stuart PM, Hendon JM, Griffith TS. Apoptosis, tolerance and regulatory $\mathrm{T}$ cells - old wine, new wineskins. Immunological Reviews. 2003;193:111-23.

11. Cohen PL, Caricchio R. Genetic models for the clearance of apoptotic cells. Rheum Dis Clin of North Am. 2004;30:473-86.

12. Huck S, Deveaud E, Namane A, Zouali M. Abnormal DNA methylation and deoxycytosine-deoxyguanine content in nucleosomes from lymphocytes undergoing apoptosis. FASEB J. 1999;13:1415-22.
13. Flierman R \& Daha MR. The clearance of apoptotic cells by complement. Immunobiology 2007;212:363-70.

14. Giovannetti A, Pierdominici M, Di Iorio A, Cianci R, Murdaca G, Puppo F, et al. Apoptosis in the Homeostasis of the Immune System and in Human Immune Mediated Diseases. Curr Pharmac Design. 2008; $14: 253-68$

15. Zhang N, Hartig H, Dzhagalov I, Draper D, He YW. The role of apoptosis in the development and function of T lymphocytes. Cell Res. 2005; 15:749-69.

16. Liphaus BL, Goldberg AC, Kiss MHB, Silva CAA. Analyses of human leukocyte antigens class II-DR in Brazilian children and adolescents with systemic lupus erythematosus. Rev Hosp Clin Fac Med São Paulo. 2002;57:277-82.

17. Liphaus BL, Kiss MHB, Goldberg AC. HLA-DRB1 alleles in juvenileonset systemic lupus erythematosus: renal histologic class correlations. Braz J Med Biol Res. 2007; 40:591-7.

18. Casciola-Rosen LA, Anhalt G, Rosen A. Autoantigens targeted in systemic lupus erythematosus are clustered in two populations of surface structures on apoptotic keratinocytes. J Exp Med. 1994;179:1317-30.

19. Emlen W, Niebur J, Kadera R. Accelerated in vitro apoptosis of lymphocytes from patients with systemic lupus erythematosus. J Immunol. 1994;152:3685-92.

20. Courtney PA, Crockard AD, Williamson K, Mcconnell J, Kennedy RJ, Bell AL. Lymphocyte apoptosis in systemic lupus erythematosus: relationships with Fas expression, serum soluble Fas and disease activity. Lupus. 1999;8:508-13.

21. Chan EY, Ko SC, Lau CS. Increased rate of apoptosis and decreased expression of bcl-2 protein in peripheral blood lymphocytes from patients with active systemic lupus erythematosus. Asian Pac J Allergy Immunol. 1997;15:3-7.

22. Dieker JW, van der Vlag J, Berden JH. Deranged removal of apoptotic cells: its role in the genesis of lupus. Nephrol Dial Transplant. 2004;19:282-5.

23. Herrmann M, Voll RE, Zoller OM, Hagenhofer M, Ponner BB, Kalden JR. Impaired phagocytosis of apoptotic cell material by monocytederived macrophages from patients with systemic lupus erythematosus. Arthritis Rheum. 1998;41:1241-50. 
24. Potter PK, Cortes-Hernandez J, Quartier P, Botto M, Walport MJ. Lupus-prone mice have an abnormal response to thioglycolate and an impaired clearance of apoptotic cells. J Immunol. 2003;170:3223-32.

25. Baumann I, Kolowos W, Voll RE, et al. Imparied uptake of apoptotic cells into tingible body macrophages in germinal centers of patients with systemic lupus erythematosus. Arthritis Rheum. 2002;46:191-201.

26. Pyrovolaki K, Mavroudi I, Sidiropolous P, Eliopoulos AG, Boumpas DT, Papadaki A. Increased Expression of CD40 on Bone Marrow CD34+ Hematopoietic Progenitor Cells in Patients with Systemic Lupus Erythematosus. Contribution to Fas-Mediated Apoptosis. Arthritis Rheum. 2009;60:543-52.

27. Drappa J, Vaishnaw AK, Sullivan KE, Chu JL, Elkon KB. Fas gene mutations in the Canele-Smith Syndrome, an inherited lymphoproliferative disorder associated with autoimmunity. N Engl J Med. 1996;335:1643-9.

28. Suda T, Takahashi T, Golstein P, Nagata S. Molecular cloning and expression of the Fas ligand: a novel member of the tumor necrosis factor family. Cell 1993;75:1169-78.

29. Ohsako S, Hara M, Harigai M, Fukasawa C, Kashiwagaki S. Expression and function of Fas antigen and Bcl-2 in human Systemic Lupus Erythematosus lymphocytes. Clin Immunol Immunophatol. 1994;73:109-14.

30. Amasaki Y, Kobayashi S, Takeda T, Ogura N, Jodo S, Nakabayashi T, Tsutsumi A, Fujisaku A, Koike T. Up-regulated expression of Fas antigen (CD95) by peripheral naive and memory $\mathrm{T}$ cell subsets in patients with systemic lupus erythematosus (SLE): a possible mechanism for lymphopenia. Clin Exp Immunol. 1995;22:245-50.

31. Bijl M, Horst G, Limburg PC, Kallenberg CG. Fas expression on peripheral blood lymphocytes in systemic lupus erythematosus (SLE): relation to lymphocyte activation and disease activity. Lupus 2001;10:866-72.

32. Suzuki N, Sakame T. Abnormal Fas and Fas ligand expression of lymphocytes in patients with SLE. Nippon Rinsho. 1996;54:1955-9.

33. Jodo S, Kobayashi S, Kayagaki N, Ogura N, Feng Y, Amasaki Y, et al. Serum levels of soluble Fas/APO-1 (CD95) and its molecular structure in patients with systemic lupus erythematosus (SLE) and other autoimmune diseases. Clin Exp Immunol. 1997;107:89-95.

34. Telegina E, Reshetnyak T, Moshnikova A, Proussakova O, Zhukova A Kuznetsova A, et al. A possible role of Fas-ligand-mediated "reserse signalling" in pathogenesis of rheumatoid arthritis and systemic lupus erythematosus. Immunol Letters 2009;122;12-17.

35. Habib HM, Taher TE, Isenberg DA, Mageed RA. Enhanced propensity of T lymphocytes in patients with systemic lupus erythematosus to apoptosis in the presence of tumour necrosis factor alpha. Scand $\mathbf{J}$ Rheumatol. 2009;38:112-20.

36. Iwai Iwai K, Miyawaki T, Takizawa T, Konno A, Otha K, Yachie A, et al. Differential Expression of Bcl-2 and Susceptibility to Anti-FasMediated Cell Death in Peripheral Blood Lymphocytes, Monocytes, and Neutrophils. Blood. 1994;84:1201-8.

37. Strasser A, Whittingham S, Vaux DL, Bath ML, Adams JM, Cory S, et al. Enforced Bcl-2 expression in B lymphoid cells prolongs antibody responses and elicits autoimmune disease. Proc Natl Acad Sci. USA 1991;88:8661-5.

38. Aringer M, Wintersberger W, Steiner CW, Kiener H, Presterl E, Jaeger $\mathrm{U}$, et al. High levels of $\mathrm{Bcl}-2$ protein in circulating $\mathrm{T}$ lymphocytes, but not B lymphocytes of patients with systemic lupus erythematosus. Arthritis Rheum. 1994;10:1423-30.
39. Mehrian R, Quismorio FP Jr, Strassmann G, Stimmler MM, Horwitz DA, Kitridou RC, et al. Synergistic effect between IL-10 and Bcl-2 genotypes in determining susceptibility to systemic lupus erythematosus. Arthritis Rheum. 1998;41:596-602.

40. Miret C, Font J, Molina R, Garcia-Carrasco M, Filella X, Ramos M, et al. Relationship of oncogenes (sFas, Bcl-2) and cytokines (IL-10, alfaTNF) with the activity of systemic lupus erythematosus. Anticancer Res. 2001;21:3053-9.

41. Falcini F, Azzari C, Gelli VAMG, Luchetti M, Gabrielli A, Calzolari A, et al. Reduction of bcl-2 in T cells during immunossupressive therapy in patients with severe juvenile onset Systemic Lupus Erythematosus. Clin Immunol. 1999;93:59-64.

42. Liphaus BL, Kiss MHB, Carrasco S, Goldenstein-Schainberg C. Increased $\mathrm{Fas}$ and $\mathrm{Bcl}-2$ expression on peripheral blood $\mathrm{T}$ and $\mathrm{B}$ lymphocytes from juvenile-onset systemic lupus erythematosus, but not from juvenile rheumatoid arthritis and juvenile dermatomyositis. Clin Dev Immunol. 2006;13:283-7.

43. Liphaus BL, Kiss MHB, Carrasco S, Goldenstein-Schainberg C. Increased Fas and Bcl-2 Expression on Peripheral Cells from Patients with Active Juvenile-Onset Systemic Lupus Erythematosus. J Rheum. 2007;34:1580-4

44. Seki M, Ushiyama C, Seta N, Abe K, Fukazawa T, Asakawa J, et al. Apoptosis of lymphocytes induced by glucocorticoids and relationship to therapeutic efficacy in patients with systemic lupus erythematosus. Arthritis Rheum. 1998;41:823-30.

45. Korb LC, Ahearm JM. C1q binds directly and specifically to surface blebs of apoptotic human keratinocytes. Complement deficiency and systemic lupus erythematosus revisited. J Immunol. 1997;158:4525-28.

46. Pickering MC, Botto M, Taylor PR, Walport MJ. Systemic Lupus Erythematosus, complement deficiency, and apoptosis. Adv Immunol 2000;76:227-34

47. Carneiro-Sampaio M, Liphaus BL, Jesus AA, Silva CAA, Oliveira JB, Kiss MH. Understanding Systemic Lupus Erythematosus Physiopathology in the Light of Primary Immunodeficiencies. J Clin Immunol. 2008;28:4-10.

48. Navratil JS, Korb LC, Ahearn JM. Systemic lupus erythematosus and complement deficiency: clues to a novel role for the classical complement pathway in the maintenance of immune tolerance. Immunopharmacology 1999;42:47-52

49. Manderson AP, Botto M, Walport MJ. The role of complement in the development of systemic lupus erythematosus. Annu Rev Immunol. 2004;22:431-56

50. Potlukova E \& Kralikova Et P. Complement Component C1q and antiC1q Antibodies in Theory and in Clinical Pratice. Scand J Immunol. 2008;67:423-30

51. Sjöholm AG, Jönsson G, Braconier JH, Sturfelt G, Truedsson L. Complement deficiency and disease: an update. Mol Immunol. 2006:43:78-85

52. Sullivan KE. Genetics of Systemic Lupus Erythematosus. Clinical implications. Rheum Dis Clin of North Am. 2000;26:229-56.

53. Prodeus AP, Goerg S, Shen LM, Pozdnyakova OO, Chu L, Alicot EM, et al. A critical role for complement in maintenance of self-tolerance. Immunity. 1998;9:721-31

54. Castellano G, Woltman AM, Nauta JA, Roos A, Trouw LA, Seelen MA, et al. Maturation of dendritic dcells abrogates $\mathrm{C} 1 \mathrm{q}$ production in vivo and in vitro. Blood. 2004; 103:3813-20. 
55. Botto M, Dell'Agnola C, Bygrave AE, Thompson EM, Cook HT, Petry F, et al. Homozygous $\mathrm{C} 1 \mathrm{q}$ deficiency causes glomerulonephritis associated with multiple apoptotic bodies. Nat Genet. 1998;19:56-9.

56. Davies KA, Erlendsson K, Beynon HL, Peters AM, Steinsson K, Valdimarsson $\mathrm{H}$, et al. Splenic uptake of immune complexes in man is complement-dependent. J Immunol. 1993; 151:3866-73.

57. Kim SJ, Gershov D, Ma X, Brot N, Elkon NB. I-PLA(2) activation during apoptosis promotes the expossure of membrane lysophosphatidylcholine leading to binding by natural immunoglobulin $\mathrm{M}$ antibodies and complement activation. J Exp Med. 2002;196:655-65.
58. Jesus AA, Silva CA, Carneiro-Sampaio M, Scheinberg M, Mangueira CL, Marie SK, et al. Anti-C1q Antibodies in Juvenile-Onset Systemic Lupus Erythematosus. Ann N Y Acad Sci. 2009;1173:235-8.

59. Bigler C, Schaller M, Perahud I, Osthoff M, Trendelenburg M. Autoantibodies against Complement C1q Specifically Target C1q Bound on Early Apoptotic Cells. J Immunol. 2009;183:3512-21. 
